\title{
PULMONARY ARTERIO-VENOUS FISTULA
}

\author{
BY \\ JAMES RONALD \\ From the Royal Northern Infirmary and Raigmore Hospital, Inverness
}

Received May 14, 1953

\begin{abstract}
Although much work has been done on arterio-venous fistulæ in the greater circulation, it is only within recent years that the importance of similar lesions affecting the pulmonary circuit has come to be recognized. While only four such cases had been reported in 1942, there are now nearly 50 recorded. The present communication adds two further cases, with features not previously described.
\end{abstract}

\section{Clinical Aspects}

As would be expected, the lesion is recognized in young to early middle life. The patient tends to be frail rather than robust, though there are exceptions to this, and there is no physical retardation. Clubbing of the fingers is frequently present, and telangiectases or hæmangiomata may be present in the skin or mucous membranes. The most common presenting symptoms are cyanosis, which sometimes dates from soon after birth, and dyspnœa; both tend to be progressive. Attacks of faintness, convulsions, or vertigo may be complained of, and epistaxis or hæmoptysis is common. Headache, cough, or venous thrombosis may be encountered.

The heart and blood pressure are within normal limits, and the circulation time is unaltered or slightly increased. Changes in the blood depend on the size of the shunt, but there is usually polycythæmia, increased blood volume, and diminished oxygen saturation. Cardiograms may show slight right axis deviation.

The lungs may be apparently normal unless the aneurysm is superficial and large, when a murmur may be heard over it. This is a very valuable sign occurring in about half the cases. The vital capacity is normal. Commonly the X-ray will show an irregular shadow, sometimes pulsatile; tomography or angiography yields valuable additional data. If the fistula is at the pulmonary bases, it may not be easily defined radiologically, as the cupola of the diaphragm or the heart shadow can obscure it. It should not be forgotten that there may be multiple fistulæ present.

The differential diagnosis lies between cyanotic congenital cardiac disease, polycythæmia rubra vera, bronchiectasis, and pulmonary tuberculosis. Treatment, if indicated, is surgical, pneumonectomy or lobectomy being the operation of choice.

Case 1. W. G., a man, aged 35 years (Dr. D. C. Wilson's patient). He was one of identical twins, his brother being healthy. He complained of having been " blue in the face " for his whole life, and of breathlessness on exertion. He was able to carry out heavy work as a cattleman, such as stacking $1 \frac{1}{2}$-cwt. bags. He had been in hospitals in 1937 and 1944 complaining of hæmoptysis, and had a further hæmoptysis prior to admission. There was no history of fits.

On admission he was a well-built man, showing marked cyanosis and clubbing of the fingers and toes. There was no distension of neck veins, nor evidence of cardiac enlargement. The heart sounds were closed, the second mitral and pulmonic sounds being accentuated. The rhythm was regular, and blood pressure was $120 / 90$. His chest showed poor expansion but no gross physical signs. Clinical examination was otherwise normal. There were no superficial telangiectases. 
The urine was normal. Blood count showed red cells 7,510,000; white cells 9,250; hæmoglobin 147 per cent. The sputum did not contain tubercle bacilli. X-ray revealed the lung fields to be hyperæmic. There was healed tuberculous infection in the right upper lobe with slight mediastinal displacement to the right. The heart shadow was within normal limits. The cardiogram showed slight left heart strain but no cardiac arrhythmia was demonstrated.

The combination of the history and findings suggested the diagnosis of pulmonary arterio-venous fistula, and he was transferred to the care of Mr. F. J. S. Gowar. Bronchoscopy showed the cords, carina, and bronchial tree to be normal. Angiocardiography showed the upper part of the right upper lung field to be relatively anæmic, and the vessels distorted. The lower branches of the right pulmonary artery were larger than those on the left, and there was simultaneous filling of large tributaries of the inferior pulmonary vein (Fig. 1). Lateral radiographs localized the lesions to the anterior part of the lower lobe of the right lung.

At operation (right lower lobe lobectomy), an indurated mass the size of a walnut lay in the apex of the lower lobe, and dilated vascular channels radiated towards its lower border. There was no thrill palpable. The pulmonary artery was large, and the basal and middle lobe arteries notably large. Examination of the resected lobe after operation showed the condition to be much more diffuse than had appeared; it was more a diffuse angiomatous condition than a localized aneurysm.

Following a stormy convalescence, the patient appeared well, and within 3 months the blood count was normal, and his clinical condition excellent. About 5 months later, however, there was slight recurrence of cyanosis and his blood count showed red cells 6,200,000 and hæmoglobin 140 per cent. A further angiogram was carried out, and the appearances strongly suggested that other vascular abnormalities were present in the base of the left lower lobe.

This case is one of multiple pulmonary arterio-venous fistulæ occurring in a man who is one of identical twins; there is no evidence of congenital abnormality in the brother.

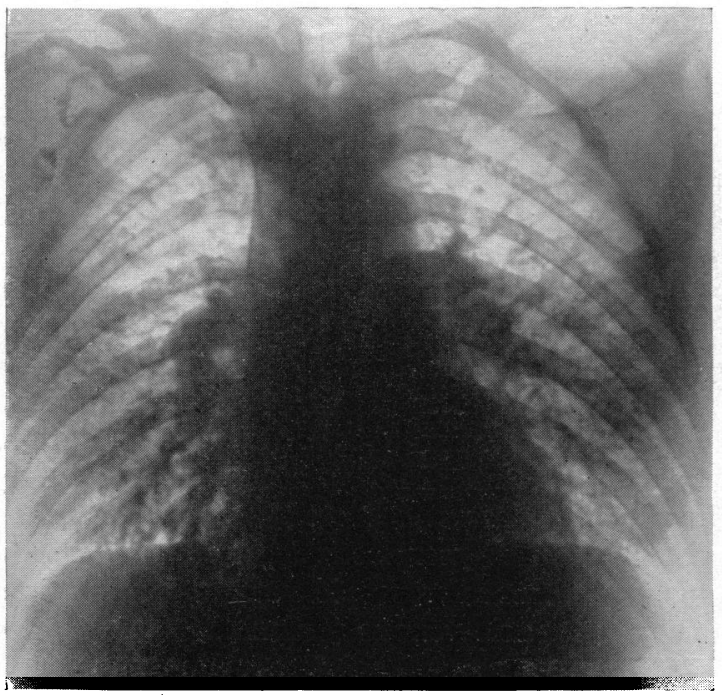

FIG. 1.-Angiocardiogram in Case 1.

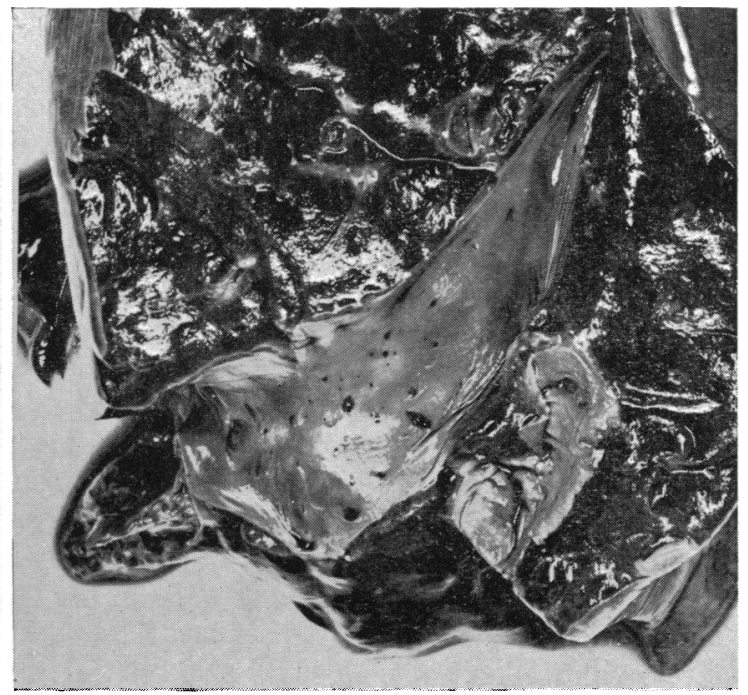

FIG. 2.-Medial aspect of left lower lobe in Case 2. Multiple communicating channels enter the large main trunk which extends to the inferior pulmonary vein at the hilum.

Case 2. This boy, aged 13 years, was admitted with a history of having had a fit during the early morning. He had apparently cried out, vomited, and become unconscious.

On admission he had recovered consciousness. He was a tall, slim, but well-developed boy, who had previously been healthy and played games in common with his schoolmates. Cerebration was normal but he had amnesia for the events of the morning. He showed no cyanosis, and there were no telangiectases or hæmangiomata detected. The pulse was irregular, rate $86 \mathrm{a}$ minute. The heart was not enlarged, and the heart sounds were closed. Posteriorly on the left, at the angle of the scapula systolic and short diastolic 
murmurs could be heard, limited to an area about the size of a penny. Blood pressure was 100/40. Neurological and general examination revealed no other abnormality.

The urine showed a trace of albumin. Blood count showed red cells 5,630,000; white cells 11,700; hæmoglobin 112 per cent. X-ray showed no abnormality of heart or lungs. The electrocardiogram showed a sinus irregularity with a wandering pacemaker. Other investigations including glucose tolerance test and lumbar puncture yielded results within normal limits. The cardiac irregularity was not significantly altered by exercise, carotid pressure, adrenalin, or atropine.

Further fits occurred at irregular intervals, on each occasion in the early hours of the morning. It was difficult to obtain an exact picture of the fits until one took place in the presence of a member of the medical staff, when it was recognized as a typical Stokes-Adams attack. He was transferred to a cardiac unit for further investigation, but before this could be carried out he developed an attack in which the heart and respiration stopped and failed to start again in spite of active therapy.

At autopsy (Dr. D. McClure) the pleural cavities were normal and free from adhesions. The lungs (right 565 g.; left 380 g.) were normal in size and shape, and showed no inflammatory reaction or œdema. Posteriorly at the margin of the left lower lobe were a group of bullous projections. These, on section, represented a plexiform mass of greatly dilated venous channels from which a large main trunk extended up to, and communicated directly with the inferior pulmonary vein at the left hilum (Fig. 2). A smaller similar mass was present on the medial anterior margin of the left upper lobe. The heart $(270 \mathrm{~g}$.) showed no valvular, myocardial, or coronary lesion, and no evidence of congenital anomaly.

The brain (1890 g.) was normal both externally and on section. The abdominal organs were healthy.

Although the provisional diagnosis made was correct, the position was initially obscure, the main clinical difficulty being the diagnosis of the fits. Once their nature was appreciated-namely that they were not of neurological origin, but Stokes-Adams attacks with ventricular arrest-the course to be adopted was clear. The child unfortunately died in an attack before the necessary specialized investigation could be undertaken.

\section{Discussion}

Congenital fistulæ are not true tumours, but developmental malformations-hamartomata. This name was introduced by Albrecht (1904), and applies to tumour-like malformations consisting of an abnormal mixture of normal components of an organ, either in quantity, arrangement, degree of differentation, or all three. In the fistulæ the fusion of venous and arterial septa is incomplete, and essentially one vascular cavity is present. Similar lesions are encountered in animals (Willis, 1948).

Variable embryonic differentiation probably accounts for the complexity of the final structure (Thompson and Shafer, 1951). The blood vessels in the embryo develop in capillary sheets or nets, and Sabin (1922) points out that individual vessels can change their functional character, serving as artery, vein, or capillary, as tissue needs alter. No indication of the later pattern of vessels is obtained until the capillary net develops to a retiform stage, in which the vascular tubes show island formation, coalescence, and fusion, leading to the formation of a definite stem. The type of vascular anomaly produced would depend on the stage at which embryological arrest occurred (de Takata, 1932). Barnes et al. (1948) have described the distension in the fistula, the hyperplastic defects in the arteries, and fibro-elastic thickening of the walls of the venous loculi, and microscopic examination in Case 2 confirmed their findings. It appears likely that the actual arterio-venous communication may not develop until after birth. Progressive expansion leads to enlargement of the lesion, with compression of the lung. It has been suggested (Brink, 1950) that the pulmonary lesions represent manifestations of hereditary telangiectasia, but this view is not generally accepted.

\section{HÆMODYNAMICS}

The effects on the circulation when an arterio-venous fistula is present in the pulmonary circuit differ from those produced by a systemic fistula.

In the systemic fistula there is an increase in the total blood volume with a proportionate increase in plasma volume and red cells; the hæmatocrit reading is essentially normal. In the pulmonary fistula the red cell mass and total blood volume are increased while the plasma volume is normal, and the hæmatocrit reading is therefore increased (Holman, 1937). Peripheral vasodilatation may 
accompany the increase in blood volume (Barnes et al., 1948), and this may account for the clubbing and the fact that the blood pressure is not raised in spite of the increased volume.

The oxyhæmoglobin saturation is normal in the systemic fistula, but decreased in the pulmonary (Maier et al., 1948).

The cardiac output is increased in the systemic fistula, sometimes greatly so; and the increase bears some relationship to the size of the communication. The right auricular pressure and heart rate are slightly increased (Cohen et al., 1948), and there may be cardiac enlargement mainly due to dilatation. Cardiac output is normal in the pulmonary fistula, and there is no enlargement.

In pulmonary arterio-venous fistula a proportion of venous blood from the pulmonary artery is shunted to the pulmonary vein without passage through the lung capillaries; venous blood returns to the left side of the heart to mix with arterial blood of the systemic circuit, giving rise to cyanosis, dyspnœa, and compensatory polycythæmia. The lung has a dual blood supply from pulmonary and bronchial systems, and either or both systems may communicate with the fistula. The part played by each varies; if cyanosis, clubbing, and polycythæmia are present the pulmonary artery and vein are undoubtedly involved. In the absence of cyanosis and polycythæmia, the bronchial arteries probably play the prominent part in supplying blood, and the presence of a murmur may also suggest this. It is probable that in Case 2 the arterial supply came from the systemic arteries (probably bronchial) though, unfortunately, these were not demonstrated in the course of the autopsy; it is likely, however, in view of the high pulse pressure and the absence of cyanosis or polycythæmia. In Case 1, on the other hand, the arterial supply was probably from the pulmonary artery. In Case 2 there was no demonstrable abnormality of the coronary system, and no evidence of embolic phenomena in the brain.

Cyanosis. The shunt allows venous blood to penetrate to the systemic circulation, and the compensatory polycythæmia is reflected in the large amount of reduced hæmoglobin in the blood.

Dyspncea. The dyspnœa develops later than the cyanosis, and is incapacitating and progressive. It is not due to pulmonary congestion, but may be related to stimulation of the respiratory centre by the high $\mathrm{CO}_{2}$ content of the arterial blood (Maier et al., 1948), or to stimulation of the sinoaortic chemoreceptors by the anoxæmia present (Hepburn et al., 1942).

Faintness. Anoxæmia is usually held to be responsible for the attacks of transient faintness, vertigo, or convulsions that may occur, on the analogy of congenital heart disease. The suggestion has been made that cerebral air embolism may take place (Lindgren, 1946), but there is no evidence to support this. It has also been put forward that small venous thromboses may occur in the cerebral tissues because of the high specific gravity of the blood, but again there is no convincing evidence. No abnormality was found on macroscopic or microscopic examination of the brain of Case 2.

Another possible mechanism which has been suggested (Peel, 1952) is that the attacks may be due to some kind of " shunt" mechanism in the lungs, whereby blood could be directed past the venous dilatations, or allowed into them; if such a shunt suddenly opened so as to allow the venous channels to fill, they would absorb a good deal of the right ventricular output for a few seconds, with consequent fall in the return to the left ventricle and transient coronary ischæmia.

On the other hand, Case 2 shows clear evidence of abnormality of cardiac rhythm (gross sinus arrhythmia with nodal escape), and his fits were Stokes-Adams attacks. These were presumably related to a series of cardiac arrhythmias with a shifting pace-maker. Some of the cardiograms showed inverted $\mathrm{T}$ waves of a type not infrequently seen after attacks of paroxysmal tachycardia (McMichael, 1951). No organic lesion was demonstrable in the heart at autopsy.

\section{SUMMARY}

Two cases of pulmonary arterio-venous fistula are reported. Of these, one occurred in a member of identical twins; the second showed clear evidence of disturbance of cardiac rhythm. The clinical and pathological picture is discussed briefly. 


\section{REFERENCES}

Adams, W. E., Thornton, T. F., and Eichelberger, L. (1944). Arch. Surg., 49, 51.

Albrecht, D. (1904). Verh. dtsch. path. Ges., 7, 153.

Baker, C., and Trounce, J. R. (1949). Brit. Heart J., 11, 109.

Barnes, C. G., Fatti, L., and Pryce, D. M. (1948). Thorax, 3, 148.

Brink, A. J. (1950). Quart. J. Med., 19, 239.

Cohen, S. M., Edholm, O. G., Howarth, S., McMichael, J., and Sharpey-Schafer, E. P. (1948). Clin. Sci., 8, 35.

De Takata, G. (1932). Surg. Gyn. Obst., 55, 227.

Hepburn, J., and Dauphinee, J. A. (1942). Amer. J. med. Sci., 204, 681.

Holman, E. (1937). Arteriovenous Aneurysm. New York.

Jones, J. C., and Thomson, W. P. (1944). J. Thorac. Surg., 13, 357.

Lindgren, E. (1946). Acta Radiol. Stockh., 27, 585.

McMichael, J. (1951). Personal communication.

Maier, H. C., Himmelstein, A., Riley, R. L., and Bunin, J. J. (1948). J. Thorac. Surg., 17, 13.

Peel, A. A. F. (1952). Personal communication.

Sabin. F. R. (1922). Contrib. Embryol. Carnegie Inst., 14, 139.

Thomson, A., and Shafer, J. C. (1951). J. Amer. med. Assoc., 145, 869.

Willis, R. A. (1948). Pathology of Tumours. London. 